\title{
Grain Boundary Blocking of Ionic Conductivity in Nanocrystalline Yttria-doped Ceria Thin Films
}

\author{
Jihwan An, ${ }^{\text {a,\# }}$ Jiwoong Bae, ${ }^{\text {b,\# }}$ Soonwook Hong, ${ }^{\text {b }}$ Bongjun Koo, ${ }^{\text {b }}$ Young-Beom Kim,,${ }^{\text {b, e,* }}$ \\ Turgut M. Gür, ${ }^{\mathrm{d}}$ and Fritz B. Prinz ${ }^{\mathrm{c}, \mathrm{d}}$
}
${ }^{a}$ Manufacturing Systems and Design Engineering (MSDE) Program, Seoul National University of Science and Technology, Seoul 139-743, Republic of Korea
${ }^{\mathrm{b}}$ Department of Mechanical Convergence Engineering, Hanyang University, Seoul 133-791, Republic of Korea
${ }^{\mathrm{c}}$ Department of Mechanical Engineering, Stanford University, Stanford, CA 94305, USA
${ }^{\mathrm{d}}$ Department of Materials Science and Engineering, Stanford University, Stanford, CA 94305, USA
${ }^{\mathrm{e}}$ Institute of Nano Science and Technology, Hanyang University, Seoul 133-791, Republic of Korea

\# These authors contributed equally to this work.

* Corresponding author

E-mail: ybkim@hanyang.ac.kr

Tel: +82-2-2220-0544

Fax: +82-2-2220-2299 


\begin{abstract}
Nanocrystalline YDC thin films with grain-sizes ranging from 38 to 93-nm were prepared using pulsed laser deposition followed by thermal annealing. Ionic conductivity decreased up to four orders of magnitude as the grain size increased. Using energy-dispersive X-ray spectroscopy, we showed that the counter-intuitive reduction in conductivity with grain-size is likely due to dopant and impurity segregation near grain-boundaries. Spectroscopic evidence suggests that the blocking effect due to defect segregation is more dominant on ionic conductivity than the grainsizes.
\end{abstract}

Keywords: Yttria-doped ceria, grain boundaries, ionic conductors, nanocrystalline materials, solid oxide fuel cell 
Nanocrystalline materials have unusual and exceptional electrical and chemical properties [13], some of which are due to their nanoscale grain sizes and highly dense grain boundaries. Compared to bulk materials, nanocrystalline films used in solid oxide fuel cells have an extremely high density of grain boundaries, and therefore, understanding the role of grain boundaries in ion transport is crucial [4-9].

There is evidence that grain boundaries affect the electrochemical properties and behavior of thin film solid oxide fuel cell (SOFC) components in two main ways. First, in terms of cathode interfacial kinetics, grain boundaries at the external surface of the solid oxide electrolyte, e.g., yttria-stabilized zirconia (YSZ), exhibit a higher surface exchange coefficient for oxygen than the bulk [10-17]. Due to dopant segregation, grain boundaries contain a higher population of oxygen vacancies than the bulk, and thus facilitate low activation energy for oxygen incorporation [14-16]. Second, previous work studying the effects of dopant distribution, space charge, as well as grain size on ionic transport across grain boundaries revealed that grain boundary resistivity is usually several orders higher than that of the bulk [18-22]. Thus, understanding the blocking effect of grain boundaries on ionic conductivity in nanocrystalline materials requires a study of how grain size and thermal history affect ion transport in nanocrystalline films.

Yttrium-doped ceria (YDC) is a promising electrolyte material for low temperature solid oxide fuel cells (LT-SOFCs) because of its superior ionic conductivity and lower activation energy for ionic transport than YSZ, which is the electrolyte material most commonly used in SOFCs $[5,23]$. Previous studies on nanocrystalline YDC examined the effects of grain size on ionic conductivity by varying the grain size using different thermal conditions to generate different grain boundary densities $[1,4,6,20,24,25]$. However, even though the effects of heat treatment on grain boundary 
density were considered in these studies, the effects of heat treatment on dopant segregation were not.

With this in mind, we investigated the effects of grain size and dopant distribution on grain boundary blocking of ionic conductivity in nanocrystalline YDC films. Through spectroscopic study and electrochemical analysis, we conclude that not only grain-boundary density, but also dopant segregation is affected by thermal treatment, which strongly influences the ionic conductivity of the films.

Nanocrystalline YDC films were deposited on a quartz substrate by pulsed laser deposition (PLD) at a substrate temperature of $750{ }^{\circ} \mathrm{C}$. A Lambda Physik $248 \mathrm{~nm} \mathrm{KrF}$ excimer laser with an energy density of $1.5 \mathrm{~J} / \mathrm{cm}^{2}$ per pulse was applied to a sintered $\mathrm{Y}_{0.1} \mathrm{Ce}_{0.9} \mathrm{O}_{2}$ target. The sample-totarget distance was $50 \mathrm{~mm}$, and PLD deposition was conducted under 100 mTorr of oxygen gas pressure. As a result, $200 \mathrm{~nm}$-thick YDC films were grown with a nominal growth rate of 0.22 Å/pulse.

To systematically control the grain size and thermal history of the YDC film, as-deposited nanocrystalline YDC films were post-annealed at $1000^{\circ} \mathrm{C}$ and $1200^{\circ} \mathrm{C}$ for 10 hours. Postannealing was conducted in an electric furnace under ambient air $\left(\mathrm{P}_{\mathrm{O}_{2}}=0.21\right.$ atm $)$ with a ramping rate of $40^{\circ} \mathrm{C} / \mathrm{min}$. Surface topography of YDC films was investigated using AFM in non-contact surface scanning mode. Chemical composition of the prepared YDC films was investigated by X-ray photoelectron spectroscopy (XPS).

After heat treatment, platinum electrode pads $(700 \mu \mathrm{m} \times 700 \mu \mathrm{m}$ in size and spaced $300 \mu \mathrm{m}$ apart) were deposited on the top surface of the $200 \mathrm{~nm}$-thick YDC films by DC sputtering for electrochemical analysis. Nanocrystalline YDC film samples with different grain sizes and thermal histories were mounted on a temperature-controlled heating stage for ionic conductivity 
measurements. Electrochemical impedance spectroscopy (EIS) was carried out using an electrochemical analyzer (Gamry Potentiostat FAS2, Gamry Instruments, Inc.) under 0 V and 1 $\mathrm{V} \mathrm{dc}$ bias. EIS measurements were performed in the frequency range of $300 \mathrm{kHz}$ to $0.5 \mathrm{~Hz}$ and between $320^{\circ} \mathrm{C}$ to $550^{\circ} \mathrm{C}$. Measured impedance data were fitted using Nyquist plots through the equivalent circuit model, and Faradaic impedances were extracted at different temperatures to obtain the activation energy for ionic conduction.

To prepare TEM-EDS samples, $50 \mathrm{~nm}$ of nanocrystalline YDC films were deposited on a TEM grid using the same PLD conditions mentioned above. After deposition, an annealing process was conducted at $1200^{\circ} \mathrm{C}$ for 10 hours on one of the two TEM samples to distinguish the morphological and stoichiometric differences between as-deposited- and $1200^{\circ} \mathrm{C}$-annealed YDC films. Areas near the $\mathrm{Y}-\mathrm{K} \alpha(14.96 \mathrm{keV})$ and $\mathrm{Ce}-\mathrm{K} \alpha(34.72 \mathrm{keV})$ peaks were integrated to compare the compositions of grain boundary and grain center regions. TEM-EDS measurements were conducted with a probe size of approximately $5 \mathrm{~nm}$.

Grain structures of the as-deposited and annealed films (50 $\mathrm{nm}$ in thickness) were investigated by TEM (Figure 1). As-deposited YDC film had an average grain size of approximately $10 \mathrm{~nm}$ in diameter, while grain size increased to approximately $50 \mathrm{~nm}$ in diameter in YDC film annealed at $1200^{\circ} \mathrm{C}$ for 10 hours, due to the grain growth mechanism. TEM images also revealed that both films consisted of vertically columnar grain structures. The formation of columnar-structured film, which is facilitated by fast surface diffusion, has been reported previously by other researchers who used similar experimental conditions [3].

We conducted TEM-EDS of the as-deposited and annealed $\left(10\right.$ hours at $\left.1200^{\circ} \mathrm{C}\right)$ films to investigate the ratio of dopant $\left(\mathrm{Y}^{3+}\right)$ concentration at the grain boundary and the grain center region according to heat treatment (Figure 2). As expected, the normalized site ratio for the $\mathrm{Ce}^{4+}$ 
ions with respect to the grain center versus the grain boundary region in the as-deposited and annealed samples are nearly the same. By contrast, however, the normalized site ratio for $\mathrm{Y}^{3+}$ at the grain boundary region to that at the grain center region in the as-deposited YDC film was $0.94 \pm 0.10$, while that in the $1200^{\circ} \mathrm{C}$-annealed sample was $1.46 \pm 0.25$. This clearly shows preferential segregation of $\mathrm{Y}^{3+}$ to grain boundaries. The uniform distribution of $\mathrm{Y}^{3+}$ concentration in the as-deposited film suggests lack of favorable conditions to drive dopant segregation to the grain boundary region. On the other hand, dopant segregation at the grain boundary was significant in the annealed film. We hypothesize that the thermal energy provided by annealing induces not only grain growth, but also segregation of dopants near grain boundaries by providing enough energy for dopant mobility [15,16,26,27].

The role of defect segregation on ionic conductivity was further studied by EIS measurements. Three samples (200 $\mathrm{nm}$ in thickness) were prepared: an as-deposited sample (deposited at $750^{\circ} \mathrm{C}$ ), and two samples annealed at $1000^{\circ} \mathrm{C}$ and at $1200^{\circ} \mathrm{C}$ for 10 hours, respectively. AFM images of the three samples are shown in Figure 3a-c. Grain sizes of the as-deposited, $1000^{\circ} \mathrm{C}$-annealed, and $1200^{\circ} \mathrm{C}$-annealed YDC films were $38 \pm 2 \mathrm{~nm}, 68 \pm 6 \mathrm{~nm}$, and $93 \pm 6 \mathrm{~nm}$, respectively.

EIS was conducted under $0 \mathrm{~V}$ and $1 \mathrm{~V}$ dc bias conditions, and in the frequency range from 300 $\mathrm{kHz}$ to $0.5 \mathrm{~Hz}$. Representative Nyquist plots for the as-deposited YDC film and $1000^{\circ} \mathrm{C}$-annealed film measured at $500^{\circ} \mathrm{C}$ are shown in Figure $3 \mathrm{~d}$. In both EIS spectra, one semicircle independent of bias conditions was observed, representing the contribution from ionic transport inside the electrolyte $[28,29]$. However, it was not possible to discern the individual contributions from the bulk and the grain boundaries in the spectra.

Ionic conductivity and activation energy were evaluated by the Arrhenius relation based on EIS data measured between $320^{\circ} \mathrm{C}$ to $550^{\circ} \mathrm{C}$ (Figure 4). Two interesting observations were made 
from the Arrhenius plot: 1) the ionic conductivity and activation energy of the as-deposited sample were comparable to those of epitaxial YDC, and 2) the ionic conductivity decreased while the activation energy increased in the annealed samples; the ionic conductivity decreased more when the sample was annealed at a higher temperature.

First, it is notable that the as-deposited film had similar ionic conductivity and activation energy $(0.97 \mathrm{eV})$ as the epitaxial or bulk YDC film, even though it had the smallest grains (highest grain-boundary density) among all three samples. The ionic conductivity of the asdeposited nanocrystalline film was also comparable to that of microcrystalline films reported elsewhere even though the density of the grain-boundary is even higher in nanocrystalline film (e.g., two orders of magnitude denser than microcrystalline film (average grain size $\sim 1-2.5 \mu \mathrm{m}$ )) $[20,23,30,31]$. Furthermore, in the nanocrystalline-doped ceria film fabricated under similar deposition conditions $\left(650^{\circ} \mathrm{C}, 1\right.$ hour), oxygen vacancies are reported to be preferentially associated with $\mathrm{Ce}^{4+}$ ions than with $\mathrm{Y}^{3+}$ ions, i.e., oxygen vacancies are distributed more uniformly, which may enhance vacancy hopping and therefore ionic conductivity [33]. This mechanism may have also contributed to the relatively high ionic conductivity of the asdeposited film.

Another notable point is that the ionic conductivity of the nanocrystalline YDC film sharply dropped by one to two orders of magnitude and the activation energy increased by $\sim 0.1 \mathrm{eV}$ after it was annealed at $1000-1200^{\circ} \mathrm{C}$ for 10 hours. This is despite the fact that the grain boundary density decreased due to grain growth, e.g., $43 \%$ decrease in $1000^{\circ} \mathrm{C}$-annealed and $59 \%$ decrease in the $1200^{\circ} \mathrm{C}$-annealed films compared to as-deposited film (determined from AFM images). Indeed, the ionic conductivity of the YDC film approached that of the grain boundary conductivity when the film was annealed: that is, ionic conduction at the grain-boundary regions 
seems to dominate the overall ionic transport. Similar trend (i.e., the higher ionic conductivity of fine-grained YDC (low sintering temperature) than coarse-grained YDC (high sintering temperature)) has been also previously reported in several papers [26, 34]. For instance, Tian et al. reported that $\mathrm{YDC}$ sintered at $1400^{\circ} \mathrm{C}$ shows higher $\mathrm{DC}$ conductivity than $\mathrm{YDC}$ sintered at $1500^{\circ} \mathrm{C}$ [26]. They argued that the larger density of grain-boundaries due to the finer grain size provides more rooms for solutes to segregate in the $1400^{\circ} \mathrm{C}$ sample than in the $1500^{\circ} \mathrm{C}$ sample. Moreover, the low mobility of dopant ions in a sample sintered at low temperature may have impeded the formation of grain-boundary structure (i.e., grain-boundary core and space charge layers). Bellino et al. also pointed out that the increase of ionic conductivity in fine-grained YDC may be due to the transition of ionic transport mechanism from brick layer model to parallel model: that is, the ionic conduction along grain-boundaries, which is faster than that in the bulk or across grain-boundaries, becomes dominant because the volume fraction of grain boundaries becomes comparable to that of bulk $[4,32,34]$. Also in such fine-grained nanocrystalline materials, neighboring space charge layers may overlap, and thus the individual grains lose their bulk properties [4,32]. Moreover, Sen et al. experimentally showed that oxygen vacancies preferentially associate with $\mathrm{Y}^{3+}$ ions rather than with $\mathrm{Ce}^{4+}$ ions in $\mathrm{YDC}$ films treated at $1400^{\circ} \mathrm{C}$ for 12 hours [33], which implies that segregation of dopant ions may have induced even more significant segregation of oxygen vacancies at the grain boundary in our annealed films. High local concentration of oxygen vacancies may induce interactions among them resulting in the generation of extended defects, which may further decrease ionic conductivity [35].

Furthermore, the lower ionic conductivity of the $1200^{\circ} \mathrm{C}$-annealed sample than that for the $1000^{\circ} \mathrm{C}$-annealed sample may also be due to silicon (found to be $<0.1$ atomic $\%$ and $<5$ 
atomic $\%$ in the $1000^{\circ} \mathrm{C}$-annealed films and in the $1200^{\circ} \mathrm{C}$-annealed films, respectively, by XPS measurement) diffusion from the substrate preferentially along grain boundaries $[18,20]$.

The extent of individual contributions of each of these factors to the observed ionic conductivity in YDC, however, is still unresolved at this point. We are currently investigating this topic in more detail in our laboratory.

In summary, the blocking effect of the grain boundary on ionic conduction in nanocrystalline YDC films was investigated with different grain sizes and thermal histories. After post-annealing, dopant segregation at the grain boundaries became significant while it was not observed in asdeposited YDC film. Concentration of oxygen vacancies due to dopant segregation may hinder ionic transport by a space charge layer effect, decreasing the ionic conductivity of annealed YDC films. As-deposited YDC film showed comparable ionic conductivity and activation energy to epitaxial YDC film, but ionic conductivity decreased as the annealing temperature increased. Spectroscopic evidence presented in this study suggests that dopant segregation has a more pronounced impact on ionic conductivity than grain size, i.e., grain boundary density.

Y.B.K. gratefully acknowledges financial support from the National Research Foundation (NRF) of the Korean Ministry of Education, Science, and Technology (MEST) (Grant No. NRF2014R1A1A2060078). J.A., T.M.G., and F.B.P. gratefully acknowledge partial support from the Center on Nanostructuring for Efficient Energy Conversion (CNEEC) at Stanford University, an Energy Frontier Research Center funded by the U.S. Department of Energy, Office of Science, Office of Basic Energy Sciences under Award Number DE-SC0001060. 
[1] J.L.M. Rupp, L.J. Gauckler, Solid State Ionics 177 (2006) 2513.

[2] J.H. Shim, C.C. Chao, H. Huang, F.B. Prinz, Chem. Mater. 19 (2007) 3850.

[3] D. Beckel, A. Bieberle-Hütter, A. Harvey, A. Infortuna, U.P. Muecke, M. Prestat, J.L.M. Rupp, L.J. Gauckler, J. Power Sources 173 (2007) 325.

[4] H.L. Tuller, Solid State Ionics 131 (2000) 143.

[5] B.C.H. Steele, Solid State Ionics 75 (1995) 157.

[6] A. Tschöpe, E. Sommer, R. Birringer, Solid State Ionics 139 (2001) 255.

[7] Y. Chem, S. Omar, A.K. Keshri, K. Balani, K. Babu, J.C. Nino, S. Seal, A. Agarwal, Scr. Mater. 60 (2009) 1023.

[8] H. Hojo, T. Mizoguchi, H. Ohta, S.D. Findlay, N. Shibata, T. Yamamoto, Y. Ikuhara, Nano Lett. 10 (2010) 4668.

[9] M. Shirpour, B. Rahmati, W. Sigle, P.A. van Aken, R. Merkle, J. Maier, J. Phys. Chem. C 116 (2012) 2453.

[10] R.A.D. Souza, M.J. Pietrowski, U. Anselmi-Tamburini, S. Kim, Z.A. Munir, M. Martin, Phys. Chem. Chem. Phys. 10 (2008) 2067.

[11] Y.B. Kim, T.P. Holme, T.M. Gür, F.B. Prinz, Adv. Funct. Mater. 21 (2011) 4684.

[12] Y.B. Kim, J.S. Park, T.M. Gür, F.B. Prinz, J. Power Sources 196 (2011) 10550.

[13] J.H. Shim, J.S. Park, T.P. Holme, K. Crabb, W. Lee, Y.B. Kim, X. Tian, T.M. Gür, F.B. Prinz, Acta Mater. 60 (2012) 1.

[14] J.S. Park, T.P. Holme, J.H. Shim, F.B. Prinz, MRS Commun. 2 (2012) 107.

[15] J. An, J.S. Park, A.L. Koh, H.B. Lee, H.J. Jung, J. Schoonman, R. Sinclair, T.M. Gür, F.B. Prinz, Sci. Rep. 3 (2013) 2680. 
[16] J. An, A.L. Koh, J.S. Park, R. Sindair, T.M. Gür, F.B. Prinz, J. Phys. Chem. Lett. 4 (2013) 1156.

[17] S.B. Adler, Chem. Rev. 104 (2004) 4791.

[18] X. Guo, J. Maier, J. Electrochem. Soc. 148 (2001) E121.

[19] J.S. Park, Y.B. Kim, J. An, F.B. Prinz, Solid St. Commun. 152 (2012) 2169.

[20] X. Guo, W. Sigle, J. Maier, J. Am. Ceram. Soc. 86 (2003) 77.

[21] O.J. Durá, M.A. López de la Torre, L. Vázquez, J. Chaboy, R. Boada, A. Rivera-Calzada, J. Santamaria, C. Leon, Phys. Rev. B 81 (2010) 184301.

[22] S. Kim, J. Maier, J. Electrochem. Soc. 149 (2002) J73.

[23] H.B. Wang, H.Z. Song, C.R. Xia, D.K. Peng, G.Y. Meng, Mater. Res. Bull. 35 (2000) 2363.

[24] E.C.C. Souza, W.C. Chueh, W. Jung, E.N.S. Muccillo, S.M. Haile, J. Electrochem. Soc. 159 (2012) K127.

[25] F. Maglia, I.G. Tredici, U. Anselmi-Tamburini, J. Eur. Ceram. Soc. 33 (2013) 1045.

[26] C. Tian, S.W. Chan, Solid State Ionics 134 (2000) 89.

[27] W. Lee, H.J. Jung, M.H. Lee, Y.B. Kim, J.S. Park, R. Sinclair, F.B. Prinz, Adv. Funct. Mater. 22 (2012) 965.

[28] R. O'Hayer, S.W. Cha, W. Colella, F.B. Prinz, Fuel cell fundamentals, second ed., John Wiley \& Sons, New York, 2009.

[29] E. Barsoukov, J.R. Macdonald, Impedance spectroscopy: theory, experiment, and applications, second ed., John Wiley \& Sons, New York, 2005.

[30] X. Guo, R. Waser, Prog. Mater. Sci. 51 (2006) 151.

[31] Y. Gu, G. Li, G. Meng, D. Peng, Mater. Res. Bull. 35 (2000) 297.

[32] J. Maier, Solid State Ionics 23 (1987) 59. 
[33] S. Sen, H.J. Avila-Paredes, S. Kim, J. Mater. Chem. 18 (2008) 3915.

[34] M.G. Bellino, D.G. Lamas, N.E. Walsöe de Reca, Adv. Funct. Mater. 16 (2006) 107.

[35] A. Nakamura, J.B. Wagner Jr., J. Electrochem. Soc. 133 (1986) 1542.

\section{FIGURE CAPTIONS}

Figure 1. Plan-view TEM images of (a) as-deposited and (b) annealed (10 hours at $\left.1200^{\circ} \mathrm{C}\right)$ YDC films (50 $\mathrm{nm}$ in thickness).

Figure 2. EDS spectra of YDC samples near (a) the Y-K $\alpha$ edge and (b) the Ce-K $\alpha$ edge in the asdeposited sample, and (c) the Y-K $\alpha$ edge and (d) the Ce-K $\alpha$ edge in the annealed sample. Spectra in red are from grain boundaries, and those in blue are from grain centers.

Figure 3. AFM images of $200 \mathrm{~nm}$-thick YDC films: (a) as-deposited, (b) annealed at $1000^{\circ} \mathrm{C}$, and (c) annealed at $1200^{\circ} \mathrm{C}$. Scale bars are $100 \mathrm{~nm}$. (d) Sample EIS spectra of as-deposited and $1000^{\circ} \mathrm{C}$-annealed YDC films at $0 \mathrm{~V}$ and $1 \mathrm{~V}$. Inset is the zoomed-in plot for $0<\mathrm{Z}_{\mathrm{RE}}<4 \mathrm{E} 6$ (ohm), and $0<-\mathrm{Z}_{\mathrm{IM}}<2 \mathrm{E} 6(\mathrm{ohm})$.

Figure 4. Arrhenius plot of as-deposited, $1000^{\circ} \mathrm{C}$-annealed, and $1200^{\circ} \mathrm{C}$-annealed samples (12 mol\% YDC). Reference data for dotted-lines, which represent the bulk (i.e., epitaxial), and grainboundary conductivities for 10 mol\% YDC are from Ref 19. 


\section{FIGURES}
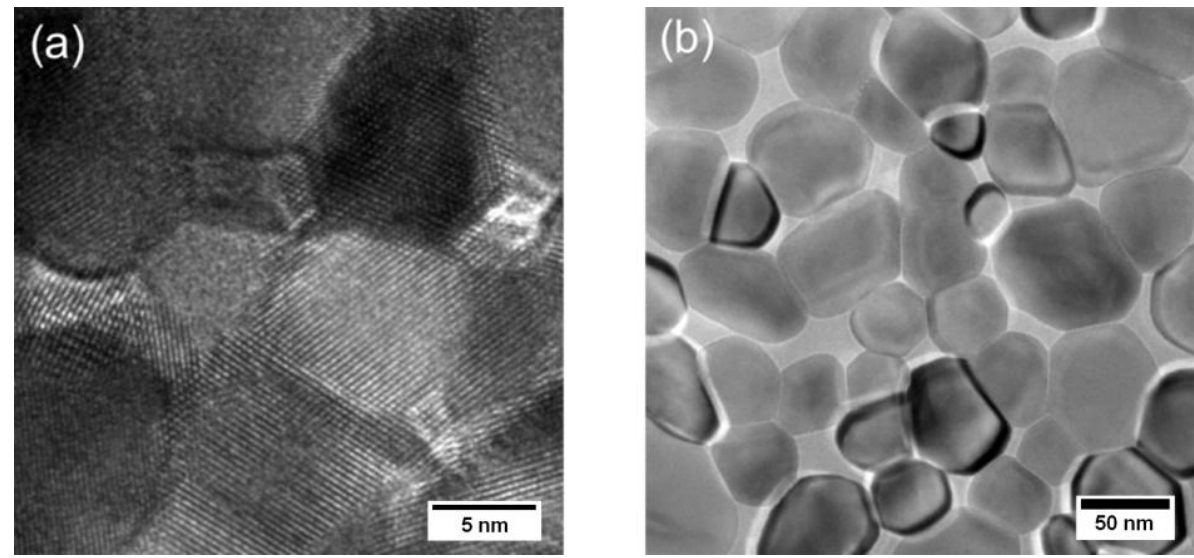

Figure 1. An et al.

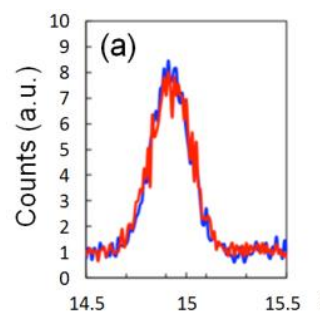

(b)
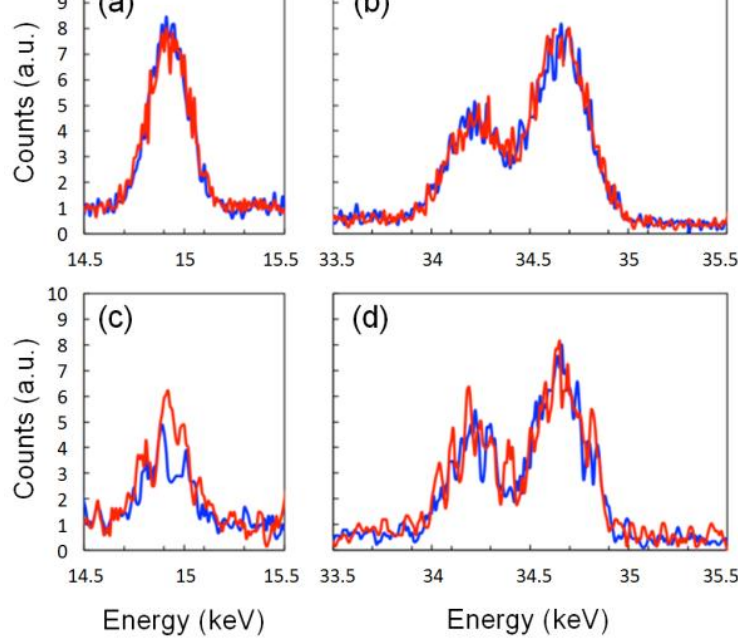

(d)

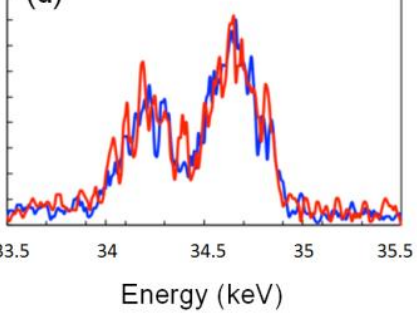

Figure 2. An et al. 

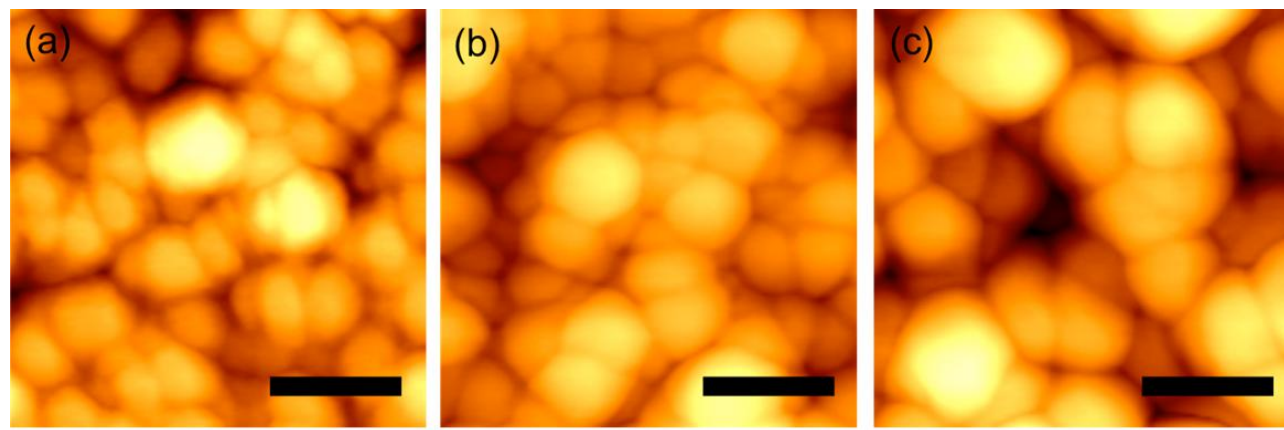

(d)

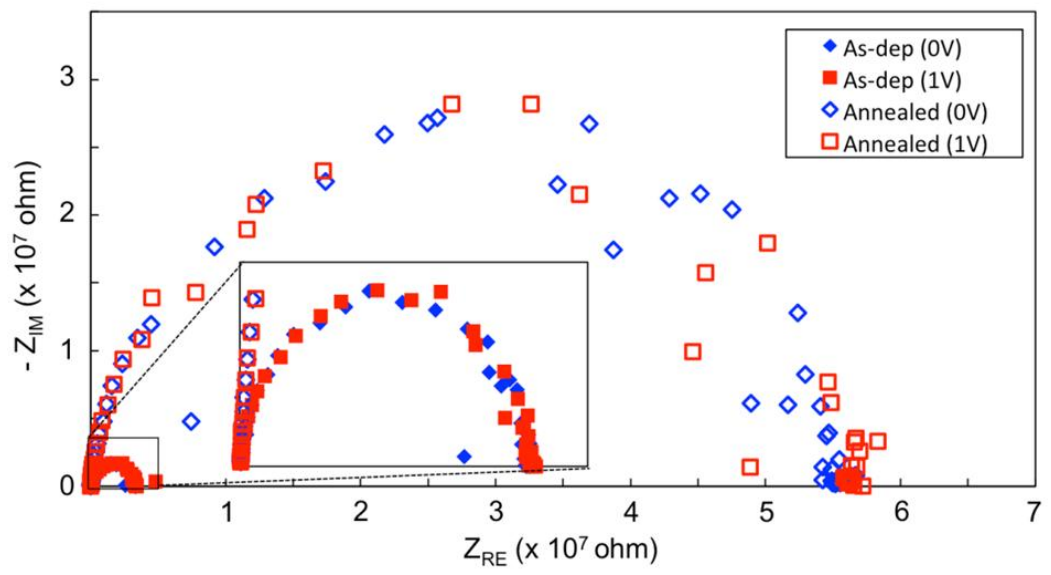

Figure 3. An et al.

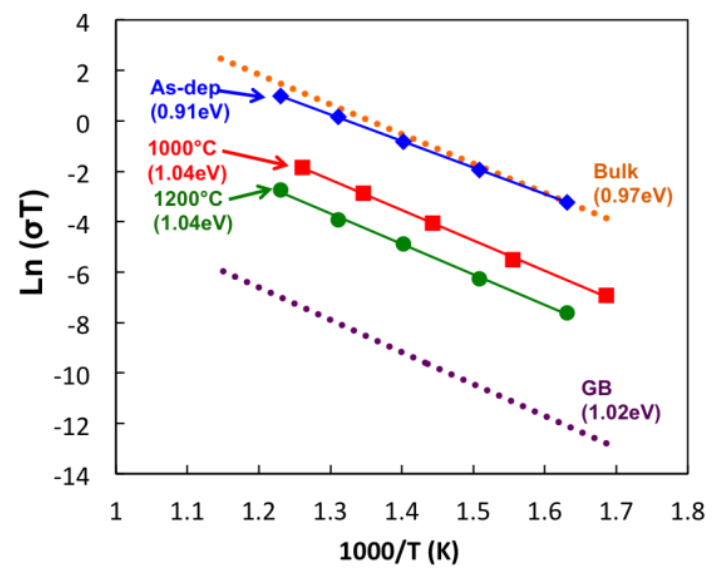

Figure 4. An et al. 